\title{
Cholesterol Metabolism in the Brain and Its Association with Parkinson's Disease
}

\author{
Uram Jin ${ }^{1,2,3 \dagger}$, Soo Jin Park ${ }^{1,2,4 \dagger}$ and Sang Myun Park ${ }^{1,2,5 *}$ \\ ${ }^{1}$ Department of Pharmacology, Ajou University School of Medicine, ${ }^{2}$ Center for Convergence Research of Neurological \\ Disorders, Ajou University School of Medicine, Departments of ${ }^{3}$ Cardiology, ${ }^{4}$ Thoracic and Cardiovascular Surgery, Ajou \\ University School of Medicine, ${ }^{5}$ BK21 Plus Program, Department of Biomedical Sciences, Ajou University School of Medicine, \\ Suwon 16499, Korea
}

Parkinson's disease (PD) is the second most progressive neurodegenerative disorder of the aging population after Alzheimer's disease (AD). Defects in the lysosomal systems and mitochondria have been suspected to cause the pathogenesis of PD. Nevertheless, the pathogenesis of PD remains obscure. Abnormal cholesterol metabolism is linked to numerous disorders, including atherosclerosis. The brain contains the highest level of cholesterol in the body and abnormal cholesterol metabolism links also many neurodegenerative disorders such as AD, PD, Huntington's disease (HD), and amyotrophic lateral sclerosis (ALS). The blood brain barrier effectively prevents uptake of lipoprotein-bound cholesterol from blood circulation. Accordingly, cholesterol level in the brain is independent from that in peripheral tissues. Because cholesterol metabolism in both peripheral tissue and the brain are quite different, cholesterol metabolism associated with neurodegeneration should be examined separately from that in peripheral tissues. Here, we review and compare cholesterol metabolism in the brain and peripheral tissues. Furthermore, the relationship between alterations in cholesterol metabolism and PD pathogenesis is reviewed.

Key words: Parkinson’s disease, Brain cholesterol, Metabolism, Neurodegeneration

\section{INTRODUCTION}

Parkinson's disease (PD) is the second most progressive neurodegenerative disorder of the aging population after Alzheimer's disease (AD). It is characterized clinically by movement symptoms, including resting tremor, rigidity, bradykinesia, and postural instability, as well as various non-motor symptoms. Pathologically, it is characterized by the loss of dopaminergic neurons in the substantia nigra pars compacta and the presence of intracellular protein inclusions called Lewy body or Lewy neurites [1]. PD is a

Received July 30, 2019, Revised October 18, 2019, Accepted October 21,2019

* To whom correspondence should be addressed. TEL: 82-31-219-5063, FAX: 82-31-219-5069 e-mail:sangmyun@ajou.ac.kr

These authors contributed equally to this work. heterogeneous disorder with both familial and sporadic forms. To date, studies in the field of Parkinsonism have identified 23 genes or loci such as a-synuclein (SNCA), parkin, PINK1, DJ-1, LRRK2, $U C H L 1$ linked to the rare monogenic familial forms of PD [2]. In addition, tremendous studies have been performed and defects in the lysosomal systems and mitochondria have been suspected to cause the pathogenesis of PD $[3,4]$. Nevertheless, the pathogenesis of $\mathrm{PD}$ remains obscure.

Cholesterol is an essential constituent of eukaryotic membranes [5]. Different concentrations of cholesterol regulate membrane fluidity, and thereby the structural integrity and functional specificity of various cellular locations, including membrane trafficking and trans-membrane signaling [6]. Especially, membrane cholesterol levels play a key factor in determining the stability and organization of microdomain termed lipid rafts [7]. Cholesterol is also the precursor of all steroid hormones and bile acids [6]. Abnormal cholesterol metabolism is linked to numerous disorders, including
Copyright (c) Experimental Neurobiology 2019.

www.enjournal.org
This is an Open Access article distributed under the terms of the Creative Commons Attribution Non-Commercial License (http://creativecommons.org/licenses/by-nc/4.0) which permits unrestricted non-commercial use, distribution, and reproduction in any medium, provided the original work is properly cited. 
atherosclerosis. In humans, the brain contains the highest level of cholesterol in the body; it contains approximately $20 \%$ of whole body cholesterol [8]. Abnormal cholesterol metabolism in the brain is also associated with many neurodegenerative disorders, such as AD, PD, Huntington's disease (HD), and amyotrophic lateral sclerosis (ALS) [9]. In addition, cholesterol lowering drugs, statins have been reported to exert beneficial effects in many neurodegenerative diseases [10]. However, it is not fully known whether the underlying mechanism of statins mediated neuroprotection is associated with lowering cholesterol level due to their pleiotrophic effects such as anti-inflammatory, anti-oxidant effects [10]. Here, we review and compare cholesterol metabolism in the brain and peripheral tissues. Furthermore, the relationship between alterations in cholesterol metabolism and PD pathogenesis is reviewed.

\section{CHOLESTEROL METABOLISM IN THE PERIPHERAL TISSUES}

\section{Cholesterol supply}

The pool of cholesterol is $2.2 \mathrm{mg} / \mathrm{g}$ body weight in the whole human body. Cholesterol is supplied by de novo biosynthesis and dietary intake. The contribution of de novo cholesterol synthesis and dietary intake to total cholesterol level in the body was estimated at a ratio of 70:30 [11]. The liver accounts for only 15\% of de novo cholesterol synthesis, and up to $85 \%$ of cholesterol synthesis occurs in organs other than the liver [12].

Most organs and tissues meet their cholesterol requirements through endogenous cholesterol biosynthesis [13]. However, many cell types have mechanisms to absorb exogenous cholesterol sources in the form of plasma-derived lipoproteins [14]. All nucleated cells in the body can synthesize cholesterol from acetyl-CoA. Cholesterol biosynthesis is a complex biochemical process involving more than 30 different reactions using more than 15 different enzymes [15]. It consists of two paths: the Bloch pathway and the Kandutsch-Russell (K-R) pathway. These pathways are the two major post-squalene cholesterol biosynthetic pathways [16, 17]. The structure of cholesterol biosynthesis pathways is significantly different between tissues [18]. The reason why cells synthesize cholesterol through different routes is not well understood; some hypotheses have been proposed. In an experiment of genetically and environmentally controlled cholesterol formation, the flux of the K-R pathway remains relatively constant, but that of the Bloch pathway changes [19]. These results showed that, unlike the Bloch pathway, the K-R pathway can ensure a certain percentage of cholesterol synthesis with a subtle change in cholesterol requirements [18]. The Bloch pathway can be a method for the production of cholesterol depending on the surrounding environment. There have been some cases of cell type-specific implementation of these pathways. The skin, muscles, and heart contain more K-R pathway components than Bloch pathway components [20]. On the contrary, in the testis and adrenal gland, which require large amounts of cholesterol, the Bloch pathway is markedly active [18].

\section{Cholesterol transfer}

Cholesterol is transferred into cells in the form of lipoproteins such as chylomicrons, very low-density lipoprotein (VLDL), intermediate-density lipoprotein (IDL), low-density lipoprotein (LDL), and high-density lipoprotein (HDL). Lipoproteins contain apolipoproteins. Apolipoproteins have several important functions, such as structural functions and roles as ligands of lipoprotein receptors, directors of the formation of lipid protein, and enzymes involved in lipoprotein metabolism [21]. Therefore, apolipoproteins play a vital role in lipoprotein metabolism. Among apolipoproteins, ApoA-I, A-II, A-IV, C-I, C-II, C-III, and E are associated with HDL, which is the main lipoprotein for cholesterol transfer [21]. Most types of apolipoprotein are produced in the liver or intestine, whereas small amount of ApoB can be produced by heart tissue and ApoE can be produced by macrophages [22].

The low-density lipoprotein receptor (LDLR) is a cell surface receptor that mediates the uptake and catabolism of ApoB or ApoE-containing plasma lipoproteins [23]. The main function of this receptor is to remove highly atherogenic LDL from blood circulation [23]. Because the liver contains 70\% of the total LDLR in the body, liver LDLR activity plays an important role in regulating plasma LDL cholesterol levels [24]. LDL receptor-related protein 1 (LRP1) is a member of the LDLR family and expressed in multiple organs, including the liver. LRP1 recognizes ApoE and is involved in the uptake of chylomicron remnants and IDL. In a similar way, ApoA-I-containing HDLs can be bound by scavenger receptor class B type I (SR-BI) in cells such as hepatocytes or endocrine cells $[25,26]$.

\section{Cholesterol turnover}

Cellular cholesterol is not generally degraded. Rather, it is stored as cholesterol ester droplets, exported to plasma lipoproteins, or converted to oxysterol, bile acids, and functionally important derivatives, such as steroids and vitamin D3 [27]. The liver is the sole organ that can remove cholesterol by secreting it into bile or converting it to bile acids. Hepatic receptors, such as LDLR, LRP1, and SR-BI bind plasma lipoproteins, eliminating excess cholesterol in the blood $[12,28]$. Cholesterol is removed from the liver by two mechanisms. Cholesterol is removed directly through the ATPbinding cassette (ABC) subfamily G5/G8 (ABCG5/G8) receptor and then excreted into the gall bladder [29]. Cholesterol is also 
converted to 7a-hydroxycholesterol by cholesterol 7a-hydroxylase, which is expressed only in the liver; this is the major mechanism of bile acid synthesis [30]. Another crucial mechanism of cholesterol turnover is cellular efflux of oxysterols derived from cholesterol [14]. Hydroxylation of cholesterol at three different positions by cholesterol 24-hydroxylase, cholesterol 25-hydroxylase, and cholesterol 27-hydroxylase produces 24-hydroxycholesterol (HC), 25$\mathrm{HC}$, and 27-HC, respectively [30]. Cholesterol 24-hydroxylase is expressed mainly in neurons and expressed at far lower levels in the liver [31]. Cholesterol 25-hydroxylase is present at a high level in the lung, but is also expressed at low levels in most tissues [32]. Cholesterol 25-hydroxylase may have a role in cholesterol catabolism in a tissue-specific manner, as does cholesterol 24-hydroxylase. $27-\mathrm{HC}$ is the most abundant cholesterol-derived oxysterol in blood circulation [33].

\section{CHOLESTEROL METABOLISM IN THE BRAIN}

\section{Cholesterol supply}

The brain contains the highest level of cholesterol in the body; it contains approximately $20 \%$ of whole body cholesterol [34]. Cholesterol in the brain is present mostly in the unesterified form, and the concentration of unesterified cholesterol in the brain is higher than that in any other tissues ( 23 mg/g) [35]. The blood brain barrier (BBB) effectively prevents the uptake of lipoprotein-bound cholesterol from blood circulation. Accordingly, cholesterol level in the brain is independent from that in peripheral tissues, and thus de novo synthesis is considered responsible for practically all cholesterol in the brain [34]. Cholesterol is mainly observed in glial cells [36] and is produced at higher rates in astrocytes than in neurons $[35,36]$. During embryogenesis, both neurons and glia actively synthesize cholesterol for myelinogenesis. However, in adults, differentiated neurons gradually lose their de novo synthetic ability and rely on lipoprotein-conjugated cholesterol produced by glia [35]. Conditional ablation of cholesterol synthesis in neurons shows no specific neurodegeneration or inflammation and no change even in the amount of cholesterol uptake receptors such as LRP1 [37]. However, the amounts of cholesterol produced by glia and taken up by neurons increase significantly [37], supporting the dependency of neurons on cholesterol produced by astrocytes. Some studies showed elevated transcript level of cholesterol synthesis enzymes in neurons compared to that in astrocytes [38]. Especially, when neurons are stimulated, such as by brain-derived neurotropic factor (BDNF), de novo synthesis of cholesterol in neurons recover to some extent [39]. In studies using radioactive labels, glia synthesize cholesterol through the Bloch pathway, as do other cholesterol forming peripheral tissues, whereas neurons synthesize cholesterol mainly through the K-R pathway [18, 36], indicating that the K-R pathway is activated in neurons to maintain homeostasis. In addition, cholesterols over than this essential cholesterol may be produced through the Bloch pathway in glia. Although cholesterol cannot cross the BBB, some cholesterols are absorbed into the brain in the form of plasma lipoprotein-bound cholesterol [40, 41]. SR-BI, which plays an important role in the selective absorption of HDL cholesterol in hepatocytes, is also present in brain capillary endothelial cells $[41,42]$, thereby mediating the uptake of cholesterol from plasma HDL and LDL [41]. Surprisingly, it has been shown that brain endothelial cells have the potential to take up LDL cholesterol through luminal LDLR and translocate this LDL across the cells [43]. However, as judged from this isotope experiments, receptor-mediated uptake of cholesterol from blood circulation yields low amount of cholesterol; thus, it is not considered important in normal conditions.

\section{Cholesterol transfer}

Most lipoproteins in plasma are not found in the brain owing to BBB [40]. Instead, a discoidal protein containing phospholipid, cholesterol, and apolipoprotein sized approximately $8 \sim 12 \mathrm{~nm}$ is identified [44]. This lipoprotein is called 'HDL-like particle because it is similar in size and density to plasma HDL [40]. Astrocytes are suspected to be mainly responsible for most of lipoprotein production in the brain [45-47]. Most of the lipoproteins found in cerebrospinal fluid (CSF) are spherical in form and different in size from nascent poorly-lipidated HDL secreted from astrocytes, suggesting that the lipoproteins secreted from astrocytes are modified as in plasma HDL maturation [48]. Some cholesterol remodeling enzymes, such as lecithin:cholesterol acyltransferase (LCAT), cholesteryl ester transfer protein (CETP), and phospholipid transfer protein (PLTP), which are known to promote spherical HDL formation from nascent HDL, were found in the brain; these proteins may play a role in brain lipoprotein maturation, although this role is yet to be clearly elucidated [49-52].

ApoE and ApoA-I are major forms of apolipoprotein found in the brain and other apolipoproteins, such as ApoJ, ApoA-II, ApoAIV, ApoD, and ApoH are observed in human CSF samples [48, 53]. These apolipoproteins form HDL-like particles, and undergo cell membrane repair and remodeling through rearrangement of cholesterol and phospholipids in differentiated adult neurons [8].

ApoE is synthesized in the brain [54], which is the second largest producer of ApoE after the liver [55]. ApoE is mainly produced in astrocytes, followed by oligodendrocytes, microglia, and ependymal layer cells [56]. In neurons, ApoE is produced when a specific stress condition or damage occurs [57]. The main function of ApoE is to regulate lipid transport between neurons and glia, as 
well as metabolism of lipoprotein-bound cholesterol [49]. ApoA-I is not synthesized in the brain, but most may be transported from plasma HDL through SR-BI-mediated uptake via the choroid plexus [41]; however, this transport mechanism is not fully understood [58].

Lipoprotein-bound cholesterols are taken up by cells via receptors in peripheral tissues. In the brain, there are seven core members including LDLR, VLDLR, ApoER2/LRP8, LRP4/MEGF7, LRP1, LRP1B, and megalin/LRP2, and three subgroups of the LDLR family, including LRP5, LRP6, and SorLA/LR11 [59, 60]. ApoE acts as a ligand for these LDLR family members expressed in the brain [60]. Among these receptors, LRP1 and LDLR are the major receptors related to ApoE-containing lipoproteins carrying cholesterol between neurons and glia [61]. LRP1 is a large endocytic receptor with various functions. In the brain, LRP1 is expressed by both neurons and glia, but predominantly by neurons [62]. LDLR is also present in both neurons and glia, however, contrary to LRP1, LDLR is more expressed in glia than in neurons [63].

\section{Cholesterol turnover}

Brain cholesterol has an extremely long half-life. In humans, the half-life of cholesterol in brain has been estimated to be between 6 months and 5 years, whereas that in plasma is only a few days [64]. Surplus cholesterol is stored in the esterified form, corresponding to $1 \%$ of total cholesterol content in the brain [65]. The level of this esterification enzyme is higher in neurons than in glia [66].

Cholesterol can be hydroxylated to 24-HC by cholesterol 24-hydroxylase and this form of oxysterol is the main form of excreted cholesterol in the brain [67]. In fact, $40 \%$ of the cholesterol released from the brain is in the 24-HC form [68]. The expression level of cholesterol 24-hydroxylase is much higher in neurons than in glia $[31,69,70]$. This oxysterol can pass lipophilic membranes, such as BBB [71]. Therefore, most 24-HC in plasma are released from the brain. Therefore, there are many attempts to use $24-\mathrm{HC}$ as a marker of the aging process or neurodegenerative disease, but this use is still debated [72-75]. Moreover, 27-HC, which is similar in character to $24-\mathrm{HC}$, is also present in the brain; however, $27-\mathrm{HC}$ is present in low amounts and most are of extracerebral origin owing to the characteristics of this oxysterol that can cross the BBB [76].

Cholesterol is also excreted from neurons through $\mathrm{ABC}$ transporters, such as ABCA1, ABCG1, and ABCG4 [77]. These ABC transporters are involved in the transport of various substances beyond the membrane, between the cells in the central nervous system (CNS) express these transporters [77]. Generally, neurons express more $\mathrm{ABC}$ transporters than astrocytes $[78,79]$. The cholesterols released via $\mathrm{ABC}$ transporters connect to the ApoA-
I-containing lipoproteins present in the CSF, and then removed through LRP1 or SR-BI, which is expressed in brain capillary endothelial cells $[48,80]$. Comparison of cholesterol metabolism between the peripheral tissues and the brain is summarized in Table 1.

\section{ALTERATIONS OF CHOLESTEROL METABOLISM IN PD}

\section{Alterations of cholesterol metabolism in human studies}

The association of cholesterol biosynthesis with the pathogenesis of PD has been rarely studied. It has been reported that cholesterol biosynthesis is decreased in fibroblasts from patients with PD owing to reduced $\beta$-Hydroxy $\beta$-methylglutaryl-CoA (HMG$\mathrm{CoA}$ ) reductase activity [81]. In addition, isopentenyl diphosphate isomerase, a cholesterol-synthesizing enzyme, is localized in Lewy bodies, proposing that cholesterol metabolites may play a role in the aggregation of $\alpha$-synuclein, enhancing Lewy body formation [82].

Several studies of serum lipid profiles in PD patients showed the inverse correlation between cholesterol level and PD. The serum levels of total cholesterol, LDL-cholesterol, VLDL-cholesterol, and triglyceride are significantly reduced in patients with PD, compared with those in the controls [83-85], which are correlated with previous study showing decrease in cholesterol biosynthesis in fibroblast from patients with PD [81]. A case control study by Huang et al. also demonstrated that low serum LDL-cholesterol level is associated with higher occurrence of PD [86]. A population based cohort study indicated that higher levels of serum total and LDL cholesterol among men over time are associated with a lower PD risk [87]. In addition, the analysis of the DATATOP trial provided that higher total serum cholesterol concentrations may be associated with a modest and slower clinical progression of PD [88]. Higher plasma LDL-cholesterol levels have been reported to be associated with better executive function and fine motor performance over time in PD [89]. In addition, the Singapore Chinese Health Study demonstrated that higher intakes of cholesterol and monounsaturated fatty acids may reduce risk of PD [90]. On the contrary, several opposite findings have also been reported. High total serum cholesterol level at baseline [91] and higher consumption of cholesterol [92] are associated with an increased risk of PD. Cross-sectional study by Cassani et al. demonstrated that HDL levels are favorably associated with duration of PD [93]. A metaanalysis has also been reported to find no significant association between serum cholesterol level and risk of PD [94].

Regarding transfer proteins, low plasma levels of ApoA-I, a major component of HDL, are found in PD [95] and associated with age at onset and motor severity in early PD patients $[95,96]$. ApoE and LRP1 immunoreactivity are increased in melanized neurons of 
Table 1. Comparison of cholesterol metabolism between the peripheral tissues and the brain

\begin{tabular}{|c|c|c|}
\hline & Peripheral tissues & Brain \\
\hline \multicolumn{3}{|l|}{ Source and synthesis of cholesterol } \\
\hline Source of cholesterol & Mainly from biosynthesis, partially from dietary intake & Almost exclusively from biosynthesis \\
\hline Cholesterol biosynthesis & Mainly extrahepatic (85\%) and partially hepatic (15\%) & $\begin{array}{l}\text { Mainly by glial cells, especially by astrocytes } \\
\text { and partially by neurons }\end{array}$ \\
\hline \multicolumn{3}{|l|}{ Cholesterol transfer } \\
\hline Lipoproteins & $\begin{array}{l}\text { Chylomicrons, chylomicron remnants, VLDL, IDL, LDL, } \\
\text { HDL, Lp (a) }\end{array}$ & HDL-like particles \\
\hline Cholesterol transfer by lipoproteins & $\begin{array}{l}\text { Mainly from peripheral tissues to the liver by HDL; partially } \\
\text { from the intestine to peripheral tissues by chylomicrons; } \\
\text { from the liver to peripheral tissues by VLDL, IDL, and LDL. }\end{array}$ & $\begin{array}{l}\text { From astrocytes and other glia to neurons by } \\
\text { HDL-like particles }\end{array}$ \\
\hline Apolipoproteins & $\begin{array}{l}\text { ApoA-I, ApoA-II, ApoA-IV, Apo-V, ApoB-48, ApoB-100, } \\
\text { ApoC-I, ApoC-II, ApoE, Apo(a), ApoJ, ApoD, etc. }\end{array}$ & ApoE, ApoA-I, ApoJ, ApoD. \\
\hline Source of apolipoproteins & Mainly from the liver and intestine. & $\begin{array}{l}\text { ApoE is produced in mainly astrocytes, fol- } \\
\text { lowed by other glia. ApoA-I is not synthesized } \\
\text { in the brain, but may be from plasma HDL. }\end{array}$ \\
\hline \multicolumn{3}{|l|}{ Cholesterol turnover } \\
\hline Turnover & $\begin{array}{l}\text { Cellularly, it is stored in the esterified form, or exported to } \\
\text { plasma lipoproteins mainly and converted into oxysterols, } \\
\text { bile acids, steroids, vitamin D3 minorly. } \\
\text { Systemically, the liver is the only organ that has ability to } \\
\text { eliminate cholesterol through its secretion into bile or its } \\
\text { transformation into bile salts. }\end{array}$ & $\begin{array}{l}\text { Cellularly, it is stored in the esterified form, } \\
\text { or converted to 24-OH-cholesterol and } \\
\text { excreted to plasma via BBB mainly. It is also } \\
\text { exported to ApoA-I containing lipopro- } \\
\text { teins, then excreted to plasma. }\end{array}$ \\
\hline
\end{tabular}

BBB, blood brain barrier; HDL, high-density lipoprotein; IDL, intermediate-density lipoprotein; LDL, low-density lipoprotein; VLDL, very low-density lipoprotein.

the substantia nigra in PD patients [97]. Despite the strong correlation between ApoE alleles and AD [98], the association between ApoE and PD may not be strong. The age at onset distribution for ApoE $\varepsilon 4 / \varepsilon 4$ was significantly earlier than that for ApoE $\varepsilon 3 / \varepsilon 3$ and $\varepsilon 2 / \varepsilon 3$ in PD [99]. The frequency of the ApoE $\varepsilon 4$ allele is increased, whereas that of the ApoE $\varepsilon 3$ allele is decreased with advancing PD pathology [100]. ApoE $\varepsilon 4$ may induce an increase in the number of cortical Lewy bodies and amyloid plaques in PD [101], suggesting similar findings in PD with AD. On the contrary, there are reports that the ApoE $\varepsilon 2$ allele, but not the ApoE $\varepsilon 4$ allele, is positively associated with sporadic PD [102], and recent large and meta-analysis studies also show that there is no association between ApoE $\varepsilon$ alleles and PD [103, 104].

Given that cholesterol metabolism in the CNS is independent on that in the periphery, measurement of cholesterol in the brain may be more important. Nevertheless, no studies measuring cholesterol level in the brain with PD have been reported. Instead, it has been reported that the level of $24-\mathrm{HC}$, which possibly reflects brain cholesterol metabolism, is decreased in the plasma of patients with PD $[105,106]$. In contrast, one study showed that $24-\mathrm{HC}$ level is increased in the CSF of patient with PD, whereas there is no difference in plasma 24-HC level between the control and patients with PD [107]. In addition, there was a significant correlation between the level of 24-HC in the CSF and the duration of the disease, which may reflect the release of 24-HC from dying neuronal cells [108].

Alterations in the lipid composition of lipid rafts, cholesterol-rich microdomains of the plasma membrane, have been reported in the autopsied brains of PD patients. The proportion of phospholipids to cholesterol in lipid rafts in the frontal cortex of PD brains appeared to be increased compared with that in control subjects, indicating a net reduction in the proportion of cholesterol in membrane rafts [109].

The association of cholesterol metabolism with PD in human studies is debatable. In addition, careful examination of neuropathology shows that AD and non-AD type proteinopathies frequently co-occur in the brains of both cognitively unimpaired and demented, aged individuals, whereas the presence of a single disease is rather the exception than the rule [110]. Given that AD has a strong association with cholesterol metabolism, attention is required in interpreting the data on cholesterol metabolism in patients with PD, especially in cases that are not confirmed by pathology.

\section{Alterations of cholesterol metabolism in model systems}

Although the association of cholesterol metabolism with PD in human studies is debatable, high level of brain cholesterol seems to aggravate the phenotype of PD in model systems. It has been 
reported that high cholesterol diet increases brain cholesterol level and exacerbates 1-methyl-4-phenyl-1,2,3,6-tetrahydropyridine (MPTP)-induced reduction of striatal dopamine and dopaminergic neurons in the substantia nigra with motor behavioral depreciation in mice [111]. In addition, the high cholesterol level incorporated into differentiated SH-SY5Y cells, a human neuroblastoma cell line, worsens dopaminergic neuronal survivability through increased depolarization of mitochondrial membrane potential [112].

In addition, many genetic factors associated with familial PD have been reported to be involved in cholesterol metabolism. Especially, accumulating evidence indicates that $\alpha$-synuclein, a major player in the pathogenesis of $\mathrm{PD}$, seems to be strongly involved in cholesterol metabolism. $\alpha$-Synuclein shares striking structural similarities with ApoE [113] and contains two cholesterol-binding domains [114]. a-Synuclein has a strong propensity to bind to lipid membranes, particularly the regions enriched in cholesterol [115]. a-Synuclein has been reported to form structures that are similar to nascent lipoproteins, which are the premature forms of the larger spherical lipoproteins (i.e., HDL) [116], and interact with lipoproteins in human plasma [117]. a-Synuclein also stimulates cholesterol efflux in SK-N-SH cells [118]. LRP1 seems to be involved in a-synuclein efflux to the periphery in mice [119]. Given that a small portion of $a$-synuclein, which is a known cytosolic protein, has been found in extracellular spaces, including human plasma and CSF [120], these data suggested that extracellular a-synuclein may function similarly to apolipoproteins, and extracellular $\alpha$-synuclein may promote cholesterol transfer. Increased cholesterol levels are observed in the brain of a-synuclein transgenic mice [121]. Brain cholesterol, cholesteryl ester, and triacylglycerol mass have also been reported to increase by 1.1-, 1.6-, and 1.4-fold, respectively, in SNCA knock out (KO) mice [122]. Cho-

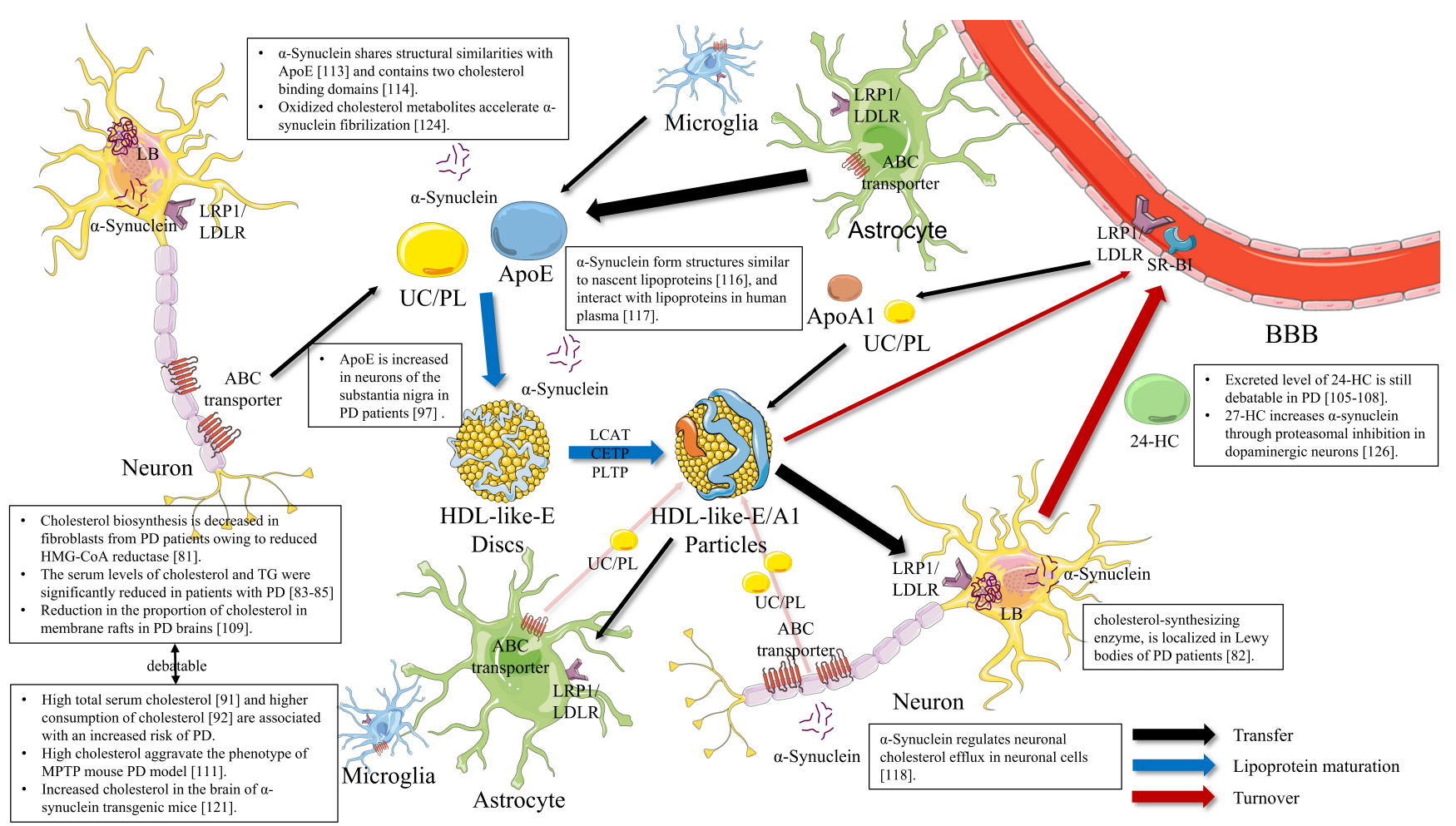

Fig. 1. Cholesterol metabolism in the brain and alteration in PD. Cholesterol is produced at higher rates in astrocytes than in neurons. Astrocytes are responsible for most of lipoprotein production (HDL-like particles) and these lipoproteins are matured in the brain. Some cholesterol remodeling enzymes such as LCAT, CETP, and PLTP were also found in the brain. ApoE and ApoA-I are major forms of apolipoprotein found in the brain. ApoE is mainly produced in astrocytes. ApoA-I is not synthesized in the brain, but transported from plasma HDL through SR-BI-mediated uptake. LRP1 and LDLR are the major receptors related to ApoE-containing lipoproteins carrying cholesterol between neurons and glia. Cholesterol can be hydroxylated to 24-HC by cholesterol 24-hydroxylase and this form of oxysterol pass lipophilic membranes, such as BBB. Cholesterol is also excreted from neurons through $\mathrm{ABC}$ transporters. Neurons express more $\mathrm{ABC}$ transporters than astrocytes. The cholesterols released via ABC transporters connect to the ApoA-I-containing lipoproteins present in the CSF, and then removed through LRP1 or SR-BI, which is expressed in brain capillary endothelial cells. CETP, cholesteryl ester transfer protein; LCAT, lecithin:cholesterol acyltransferase; PLTP, phospholipid transfer protein. The schematic art pieces used in this figure were provided by Servier Medical art (http://servier.com/Powerpoint-image-bank). Servier Medical Art by Servier is licensed under a Creative Commons Attribution 3.0 Unported License. 
Table 2. The relationship between cholesterol and Parkinson's disease

\begin{tabular}{|c|c|c|}
\hline & Findings & References \\
\hline \multicolumn{3}{|l|}{ Human studies } \\
\hline$\downarrow$ Cholesterol synthesis & $\begin{array}{l}\text { Cholesterol biosynthesis is decreased in fibroblasts from patients with PD owing to reduced HMG- } \\
\text { CoA reductase activity. }\end{array}$ & {$[81]$} \\
\hline \multirow[t]{4}{*}{$\downarrow$ Serum cholesterol levels } & $\begin{array}{l}\text { The serum levels of total cholesterol, LDL-cholesterol, VLDL-cholesterol, and triglyceride are re- } \\
\text { duced in patients with PD. }\end{array}$ & [83-85] \\
\hline & $\begin{array}{l}\text { Low serum total or LDL-cholesterol level is associated with higher occurrence of PD, faster clinical } \\
\text { progression or more severe symptoms in PD patients. }\end{array}$ & {$[86,87]$} \\
\hline & Low total cholesterol level is associated with faster clinical progression. & [88] \\
\hline & Low serum LDL-cholesterol level is associated with more severe symptoms in PD patients. & [89] \\
\hline \multirow[t]{2}{*}{$\downarrow$ Plasma ApoA-I level } & Low plasma levels of ApoA-I are found in PD. & [95] \\
\hline & Low plasma levels of ApoA-I are associated with age at onset and motor severity in early PD patients. & {$[95,96]$} \\
\hline$\downarrow$ Plasma 24-HC[128] level & The level of $24-\mathrm{HC}$ is decreased in the plasma of patients with PD. & {$[105,106]$} \\
\hline$\uparrow$ CSF 24-HC level & 24-HC level is increased in the CSF of patient with PD. & {$[107]$} \\
\hline $\begin{array}{l}\downarrow \text { Cholesterol proportion in } \\
\text { membrane lipid rafts }\end{array}$ & The proportion of cholesterol in membrane lipid rafts appeared to be reduced in PD brains. & {$[109]$} \\
\hline \multicolumn{3}{|l|}{ Model studies } \\
\hline \multirow[t]{2}{*}{ MPTP model } & $\begin{array}{l}\text { Hypercholesterolemia exacerbate MPTP-induced reduction of striatal dopamine and dopaminergic } \\
\text { neurons in the substantia nigra with motor behavioral depreciation in mice. }\end{array}$ & [111] \\
\hline & $\begin{array}{l}\text { The high cholesterol level incorporated into differentiated SH-SY5Y cells worsens dopaminergic } \\
\text { neuronal survivability. }\end{array}$ & {$[112]$} \\
\hline \multirow[t]{6}{*}{ a-Synuclein } & Cholesterol mediates the interaction of oligomeric $a$-synuclein with the cell membrane. & {$[123]$} \\
\hline & $\begin{array}{l}\text { Elevated levels of oxidized cholesterol metabolites in Lewy body disease brains accelerate } \\
\text { a-synuclein fibrilization. }\end{array}$ & [124] \\
\hline & a-Synuclein aggregation increases at low concentrations of ApoE. & {$[125]$} \\
\hline & $\begin{array}{l}\text { 27-HC increases } a \text {-synuclein protein levels through proteasomal inhibition in human dopaminer- } \\
\text { gic neurons. }\end{array}$ & {$[126]$} \\
\hline & Cholesterol levels is increased in the brain of a-synuclein transgenic mice. & {$[121]$} \\
\hline & Brain cholesterol, cholesteryl ester, and triacylglycerol mass are increased in $\alpha$-synuclein $\mathrm{KO}$ mice. & {$[122]$} \\
\hline \multirow[t]{2}{*}{ Parkin } & $\begin{array}{l}\text { Total cholesterol level is increased and the membrane fluidity is decreased in parkin deficient MEF } \\
\text { cells, causing dysregulation of lipid rafts-dependent endocytosis }\end{array}$ & {$[128]$} \\
\hline & The increase in serum cholesterol level by high fat diet is less pronounced in parkin KO mice. & [129] \\
\hline PINK1 & PINK1 is associated with lipid rafts in in vitro models. & [137] \\
\hline \multirow[t]{3}{*}{ DJ-1 } & $\begin{array}{l}\text { DJ-1 deficiency in astrocytes causes decrease in cellular cholesterol level, increase in membrane } \\
\text { fluidity, and decrease in lipid rafts-dependent endocytosis. }\end{array}$ & {$[131,132]$} \\
\hline & $\begin{array}{l}\text { Cholesterol supplementation rescues the synaptic endocytic defects observed in DJ-1-deficient } \\
\text { neurons. }\end{array}$ & [133] \\
\hline & Expression of LDLR mRNA and protein were reduced in DJ-1-knockdown cells and DJ-1 KO mice. & {$[134]$} \\
\hline LRRK2 & The plasma cholesterol level is elevated in LRRK2 KO rats. & {$[135]$} \\
\hline UCH-L1 & UCH-L1 is associated with lipid rafts in in vitro models. & [139] \\
\hline
\end{tabular}

CSF, cerebrospinal fluid; HC, hydroxycholesterol; HMG-CoA, $\beta$-Hydroxy $\beta$-methylglutaryl-CoA; KO, knock out; MEF, mouse embryonic fibroblast; LDL, low-density lipoprotein; MPTP, 1-methyl-4-phenyl-1,2,3,6-tetrahydropyridine; PD, Parkinson's disease; VLDL, very low-density lipoprotein.

lesterol also mediates the interaction of oligomeric a-synuclein with the cell membrane, which leads to membrane disruption and cell death [123]. Elevated levels of oxidized cholesterol metabolites in Lewy body disease brains accelerate $\alpha$-synuclein fibrilization [124]. a-Synuclein aggregation increases at low concentrations of ApoE and decreases at high concentrations of ApoE [125]. 27-HC increases a-synuclein protein levels through proteasomal inhibition in human dopaminergic neurons [126], suggesting that dysfunctions of cholesterol metabolism may also induce the aggregation of $a$-synuclein, thus causing PD. These studies suggested that a-synuclein may influence cholesterol metabolism and cholesterol may also contribute to the aggregation of $\alpha$-synuclein.

A E3 ubiquitin ligase, parkin, of which genetic mutations were considered a common cause of early onset PD [127], is also associated with cholesterol metabolism. It has been reported that the total cellular cholesterol level is increased and the membrane fluidity is decreased in parkin deficient mouse embryonic fibroblast (MEF) cells, causing dysregulation of lipid rafts-dependent endocytosis [128]. Parkin has also been reported to be a lipid-responsive regulator of fat uptake, and the increase in serum cholesterol level by high fat diet is less pronounced in parkin KO mice [129].

DJ-1, a multifunctional protein and a causative gene product as- 
sociated with autosomal recessive familial PD [130], has also been reported to be associated with cholesterol metabolism. DJ-1 deficiency in astrocytes causes decrease in cellular cholesterol level, increase in membrane fluidity, and decrease in lipid rafts-dependent endocytosis [131, 132]. In addition, cholesterol supplementation rescues the synaptic endocytic defects observed in DJ-1-deficient neurons [133]. Reduced expression of LDLR mRNA and protein was observed in DJ-1-knockdown cells and DJ-1 KO mice [134].

Elevated plasma cholesterol level in leucine-rich repeat kinase 2 (LRRK2) KO rats has also been reported [135]. In addition, parkin, PINK1, DJ-1, LRRK2, and ubiquitin carboxy-terminal hydrolase L1 (UCH-L1) have been reported to be associated with lipid rafts in in vitro models [131, 136-139].

The molecular pathways of neurodegeneration triggered by each mutation may be shared by several genetic forms of PD, and may also play a common role in its pathogenesis. Accordingly, given the fact that each mutation of genetic factors alters cholesterol metabolism, alterations in cholesterol metabolism can contribute to the pathogenesis of PD. Cholesterol metabolism in the brain and reported association with PD is illustrated in Fig. 1 and the relationship between cholesterol and PD is summarized in Table 2 .

\section{CONCLUSIONS}

The brain is the most cholesterol-rich organ, and owing to the $\mathrm{BBB}$, cholesterol metabolism in the brain is independent on that in peripheral tissues. Nevertheless, detailed knowledge on cholesterol metabolism in the brain remains incomplete, and it should be considered that altered cholesterol metabolism in the periphery does not represent that in the CNS. In addition, most studies have analyzed the features of CSF lipoprotein. Although the brain and CSF are interconnected, the features of lipoproteins in CSF are not the same as those in the brain. Not much is known about the composition of lipoproteins in brain and how CSF lipoproteins communicates with lipoproteins in the brain. It may cause the discrepancy between human studies and model studies, in addition to several limitations of human studies including measuring cholesterol level in the plasma, not in the brain with PD patients as described above. Although the relationship between cholesterol metabolism in the CNS and pathogenesis of PD has not been wellstudied, given that many PD-related gene products are involved in cholesterol metabolism, further studies of cholesterol metabolism in PD may provide clues to elucidate unsolved pathogenesis of PD.

\section{ACKNOWLEDGEMENTS}

This research was supported by the National Research
Foundation of Korea (NRF) grants funded by the Korean government (Ministry of Science and ICT) (Grant No. 2017R1E1A1A91973713, NRF-2019R1A5A2026045).

\section{REFERENCES}

1. Kalia LV, Lang AE (2015) Parkinson's disease. Lancet 386:896912.

2. Karimi-Moghadam A, Charsouei S, Bell B, Jabalameli MR (2018) Parkinson disease from mendelian forms to genetic susceptibility: new molecular insights into the neurodegeneration process. Cell Mol Neurobiol 38:1153-1178.

3. Plotegher N, Duchen MR (2017) Crosstalk between lysosomes and mitochondria in Parkinson's disease. Front Cell Dev Biol 5:110.

4. Zhang J, Culp ML, Craver JG, Darley-Usmar V (2018) Mitochondrial function and autophagy: integrating proteotoxic, redox, and metabolic stress in Parkinson's disease. J Neurochem 144:691-709.

5. Yeagle PL (1991) Modulation of membrane function by cholesterol. Biochimie 73:1303-1310.

6. Schroeder F, Jefferson JR, Kier AB, Knittel J, Scallen TJ, Wood WG, Hapala I (1991) Membrane cholesterol dynamics: cholesterol domains and kinetic pools. Proc Soc Exp Biol Med 196:235-252.

7. Korade Z, Kenworthy AK (2008) Lipid rafts, cholesterol, and the brain. Neuropharmacology 55:1265-1273.

8. Mahley RW (2016) Central nervous system lipoproteins: ApoE and regulation of cholesterol metabolism. Arterioscler Thromb Vasc Biol 36:1305-1315.

9. Martín MG, Pfrieger F, Dotti CG (2014) Cholesterol in brain disease: sometimes determinant and frequently implicated. EMBO Rep 15:1036-1052.

10. Saeedi Saravi SS, Saeedi Saravi SS, Arefidoust A, Dehpour AR (2017) The beneficial effects of HMG-CoA reductase inhibitors in the processes of neurodegeneration. Metab Brain Dis 32:949-965.

11. Grundy SM (1983) Absorption and metabolism of dietary cholesterol. Annu Rev Nutr 3:71-96.

12. Dietschy JM (1997) Theoretical considerations of what regulates low-density-lipoprotein and high-density-lipoprotein cholesterol. Am J Clin Nutr 65(5 Suppl):1581S-1589S.

13. Dietschy JM, Turley SD, Spady DK (1993) Role of liver in the maintenance of cholesterol and low density lipoprotein homeostasis in different animal species, including humans. J Lipid Res 34:1637-1659.

14. Tabas I (2002) Consequences of cellular cholesterol accumu- 
lation: basic concepts and physiological implications. J Clin Invest 110:905-911.

15. Sharpe LJ, Brown AJ (2013) Controlling cholesterol synthesis beyond 3-hydroxy-3-methylglutaryl-CoA reductase (HMGCR). J Biol Chem 288:18707-18715.

16. Kandutsch AA, Russell AE (1960) Preputial gland tumor sterols. 3. A metabolic pathway from lanosterol to cholesterol. J Biol Chem 235:2256-2261.

17. Bloch K (1965) The biological synthesis of cholesterol. Science 150:19-28.

18. Mitsche MA, McDonald JG, Hobbs HH, Cohen JC (2015) Flux analysis of cholesterol biosynthesis in vivo reveals multiple tissue and cell-type specific pathways. Elife 4:e07999.

19. Rawson RB, DeBose-Boyd R, Goldstein JL, Brown MS (1999) Failure to cleave sterol regulatory element-binding proteins (SREBPs) causes cholesterol auxotrophy in Chinese hamster ovary cells with genetic absence of SREBP cleavage-activating protein. J Biol Chem 274:28549-28556.

20. Okamoto T, Moroyama T, Morita T, Yoshiga K, Takada K, Okuda K (1984) Differentiation of cultured epidermal keratinocytes related to sterol metabolism and its retardation by chemical carcinogens. Biochim Biophys Acta 805:143-151.

21. Ramasamy I (2014) Recent advances in physiological lipoprotein metabolism. Clin Chem Lab Med 52:1695-1727.

22. Arnold PO, Cholesterol KJ (2003) Absorption, function, and metabolism. In: Encyclopedia of food sciences and nutrition (Caballero B, Trugo L, Finglas M, eds), Academic Press, San Diego.

23. Brown MS, Goldstein JL (1986) A receptor-mediated pathway for cholesterol homeostasis. Science 232:34-47.

24. Bilheimer DW, Goldstein JL, Grundy SM, Starzl TE, Brown MS (1984) Liver transplantation to provide low-densitylipoprotein receptors and lower plasma cholesterol in a child with homozygous familial hypercholesterolemia. N Engl J Med 311:1658-1664.

25. Acton S, Rigotti A, Landschulz KT, Xu S, Hobbs HH, Krieger M (1996) Identification of scavenger receptor SR-BI as a high density lipoprotein receptor. Science 271:518-520.

26. Landschulz KT, Pathak RK, Rigotti A, Krieger M, Hobbs HH (1996) Regulation of scavenger receptor, class B, type I, a high density lipoprotein receptor, in liver and steroidogenic tissues of the rat. J Clin Invest 98:984-995.

27. Steck TL, Lange Y (2010) Cell cholesterol homeostasis: mediation by active cholesterol. Trends Cell Biol 20:680-687.

28. Krieger M (1999) Charting the fate of the "good cholesterol": identification and characterization of the high-density lipoprotein receptor SR-BI. Annu Rev Biochem 68:523-558.
29. Repa JJ, Berge KE, Pomajzl C, Richardson JA, Hobbs H, Mangelsdorf DJ (2002) Regulation of ATP-binding cassette sterol transporters ABCG5 and ABCG8 by the liver X receptors alpha and beta. J Biol Chem 277:18793-18800.

30. Russell DW (2003) The enzymes, regulation, and genetics of bile acid synthesis. Annu Rev Biochem 72:137-174.

31. Lund EG, Guileyardo JM, Russell DW (1999) cDNA cloning of cholesterol 24-hydroxylase, a mediator of cholesterol homeostasis in the brain. Proc Natl Acad Sci U S A 96:72387243.

32. Lund EG, Kerr TA, Sakai J, Li WP, Russell DW (1998) cDNA cloning of mouse and human cholesterol 25-hydroxylases, polytopic membrane proteins that synthesize a potent oxysterol regulator of lipid metabolism. J Biol Chem 273:3431634327.

33. Dzeletovic S, Breuer O, Lund E, Diczfalusy U (1995) Determination of cholesterol oxidation products in human plasma by isotope dilution-mass spectrometry. Anal Biochem 225:7380.

34. Björkhem I, Meaney S (2004) Brain cholesterol: long secret life behind a barrier. Arterioscler Thromb Vasc Biol 24:806815.

35. Dietschy JM, Turley SD (2004) Thematic review series: brain Lipids. Cholesterol metabolism in the central nervous system during early development and in the mature animal. J Lipid Res 45:1375-1397.

36. Nieweg K, Schaller H, Pfrieger FW (2009) Marked differences in cholesterol synthesis between neurons and glial cells from postnatal rats. J Neurochem 109:125-134.

37. Fünfschilling U, Saher G, Xiao L, Möbius W, Nave KA (2007) Survival of adult neurons lacking cholesterol synthesis in vivo. BMC Neurosci 8:1.

38. Valdez CM, Smith MA, Perry G, Phelix CF, Santamaria F (2010) Cholesterol homeostasis markers are localized to mouse hippocampal pyramidal and granule layers. Hippocampus 20:902-905.

39. Liu Q, Trotter J, Zhang J, Peters MM, Cheng H, Bao J, Han X, Weeber EJ, Bu G (2010) Neuronal LRP1 knockout in adult mice leads to impaired brain lipid metabolism and progressive, age-dependent synapse loss and neurodegeneration. J Neurosci 30:17068-17078.

40. Vitali C, Wellington CL, Calabresi L (2014) HDL and cholesterol handling in the brain. Cardiovasc Res 103:405-413.

41. Balazs Z, Panzenboeck U, Hammer A, Sovic A, Quehenberger O, Malle E, Sattler W (2004) Uptake and transport of highdensity lipoprotein (HDL) and HDL-associated alphatocopherol by an in vitro blood-brain barrier model. J Neuro- 
chem 89:939-950.

42. Rigotti A, Trigatti B, Babitt J, Penman M, Xu S, Krieger M (1997) Scavenger receptor BI--a cell surface receptor for high density lipoprotein. Curr Opin Lipidol 8:181-188.

43. Dehouck B, Dehouck MP, Fruchart JC, Cecchelli R (1994) Upregulation of the low density lipoprotein receptor at the blood-brain barrier: intercommunications between brain capillary endothelial cells and astrocytes. J Cell Biol 126:465473.

44. Ladu MJ, Reardon C, Van Eldik L, Fagan AM, Bu G, Holtzman D, Getz GS (2000) Lipoproteins in the central nervous system. Ann NY Acad Sci 903:167-175.

45. Boyles JK, Pitas RE, Wilson E, Mahley RW, Taylor JM (1985) Apolipoprotein E associated with astrocytic glia of the central nervous system and with nonmyelinating glia of the peripheral nervous system. J Clin Invest 76:1501-1513.

46. Fagan AM, Holtzman DM, Munson G, Mathur T, Schneider D, Chang LK, Getz GS, Reardon CA, Lukens J, Shah JA, LaDu MJ (1999) Unique lipoproteins secreted by primary astrocytes from wild type, apoE (-/-), and human apoE transgenic mice. J Biol Chem 274:30001-30007.

47. Navarro A, Méndez E, Diaz C, del Valle E, Martínez-Pinilla E, Ordóñez C, Tolivia J (2013) Lifelong expression of apolipoprotein $\mathrm{D}$ in the human brainstem: correlation with reduced age-related neurodegeneration. PLoS One 8:e77852.

48. Koch S, Donarski N, Goetze K, Kreckel M, Stuerenburg HJ, Buhmann C, Beisiegel U (2001) Characterization of four lipoprotein classes in human cerebrospinal fluid. J Lipid Res 42:1143-1151.

49. Vance JE, Hayashi H (2010) Formation and function of apolipoprotein E-containing lipoproteins in the nervous system. Biochim Biophys Acta 1801:806-818.

50. Albers JJ, Tollefson JH, Wolfbauer G, Albright RE Jr (1992) Cholesteryl ester transfer protein in human brain. Int J Clin Lab Res 21:264-266.

51. Zhou T, He Q, Tong Y, Zhan R, Xu F, Fan D, Guo X, Han H, Qin S, Chui D (2014) Phospholipid transfer protein (PLTP) deficiency impaired blood-brain barrier integrity by increasing cerebrovascular oxidative stress. Biochem Biophys Res Commun 445:352-356.

52. Vuletic S, Jin LW, Marcovina SM, Peskind ER, Moller T, Albers JJ (2003) Widespread distribution of PLTP in human CNS: evidence for PLTP synthesis by glia and neurons, and increased levels in Alzheimer's disease. J Lipid Res 44:11131123.

53. Demeester N, Castro G, Desrumaux C, De Geitere C, Fruchart JC, Santens P, Mulleners E, Engelborghs S, De Deyn
PP, Vandekerckhove J, Rosseneu M, Labeur C (2000) Characterization and functional studies of lipoproteins, lipid transfer proteins, and lecithin:cholesterol acyltransferase in CSF of normal individuals and patients with Alzheimer's disease. J Lipid Res 41:963-974.

54. Linton MF, Gish R, Hubl ST, Bütler E, Esquivel C, Bry WI, Boyles JK, Wardell MR, Young SG (1991) Phenotypes of apolipoprotein B and apolipoprotein E after liver transplantation. J Clin Invest 88:270-281.

55. Elshourbagy NA, Liao WS, Mahley RW, Taylor JM (1985) Apolipoprotein E mRNA is abundant in the brain and adrenals, as well as in the liver, and is present in other peripheral tissues of rats and marmosets. Proc Natl Acad Sci U S A 82:203-207.

56. Mahley RW, Weisgraber KH, Huang Y (2006) Apolipoprotein E4: a causative factor and therapeutic target in neuropathology, including Alzheimer's disease. Proc Natl Acad Sci U S A 103:5644-5651.

57. Xu Q, Bernardo A, Walker D, Kanegawa T, Mahley RW, Huang Y (2006) Profile and regulation of apolipoprotein E (ApoE) expression in the CNS in mice with targeting of green fluorescent protein gene to the ApoE locus. J Neurosci 26:49854994.

58. Stukas S, Robert J, Lee M, Kulic I, Carr M, Tourigny K, Fan J, Namjoshi D, Lemke K, DeValle N, Chan J, Wilson T, Wilkinson A, Chapanian R, Kizhakkedathu JN, Cirrito JR, Oda MN, Wellington CL (2014) Intravenously injected human apolipoprotein A-I rapidly enters the central nervous system via the choroid plexus. J Am Heart Assoc 3:e001156.

59. Herz J (2009) ApoE receptors in the nervous system. Curr Opin Lipidol 20:190-196.

60. Bu G (2009) Apolipoprotein E and its receptors in Alzheimer's disease: pathways, pathogenesis and therapy. Nat Rev Neurosci 10:333-344.

61. Holtzman DM, Herz J, Bu G (2012) Apolipoprotein E and apolipoprotein E receptors: normal biology and roles in $\mathrm{Al}$ zheimer disease. Cold Spring Harb Perspect Med 2:a006312.

62. Moestrup SK, Gliemann J, Pallesen G (1992) Distribution of the alpha 2-macroglobulin receptor/low density lipoprotein receptor-related protein in human tissues. Cell Tissue Res 269:375-382.

63. Rebeck GW, Reiter JS, Strickland DK, Hyman BT (1993) Apolipoprotein $\mathrm{E}$ in sporadic Alzheimer's disease: allelic variation and receptor interactions. Neuron 11:575-580.

64. Björkhem I, Lütjohann D, Diczfalusy U, Ståhle L, Ahlborg G, Wahren J (1998) Cholesterol homeostasis in human brain: turnover of 24S-hydroxycholesterol and evidence for a cere- 
bral origin of most of this oxysterol in the circulation. J Lipid Res 39:1594-1600.

65. Bryleva EY, Rogers MA, Chang CC, Buen F, Harris BT, Rousselet E, Seidah NG, Oddo S, LaFerla FM, Spencer TA, Hickey WF, Chang TY (2010) ACAT1 gene ablation increases 24(S)hydroxycholesterol content in the brain and ameliorates amyloid pathology in mice with AD. Proc Natl Acad Sci U S A 107:3081-3086.

66. Sakashita N, Miyazaki A, Takeya M, Horiuchi S, Chang CC, Chang TY, Takahashi K (2000) Localization of human acylcoenzyme A: cholesterol acyltransferase-1 (ACAT-1) in macrophages and in various tissues. Am J Pathol 156:227-236.

67. Zhang J, Liu Q (2015) Cholesterol metabolism and homeostasis in the brain. Protein Cell 6:254-264.

68. Russell DW, Halford RW, Ramirez DM, Shah R, Kotti T (2009) Cholesterol 24-hydroxylase: an enzyme of cholesterol turnover in the brain. Annu Rev Biochem 78:1017-1040.

69. Lund EG, Xie C, Kotti T, Turley SD, Dietschy JM, Russell DW (2003) Knockout of the cholesterol 24-hydroxylase gene in mice reveals a brain-specific mechanism of cholesterol turnover. J Biol Chem 278:22980-22988.

70. Lütjohann D, Breuer O, Ahlborg G, Nennesmo I, Sidén A, Diczfalusy U, Björkhem I (1996) Cholesterol homeostasis in human brain: evidence for an age-dependent flux of $24 \mathrm{~S}$ hydroxycholesterol from the brain into the circulation. Proc Natl Acad Sci U S A 93:9799-9804.

71. Meaney S, Bodin K, Diczfalusy U, Björkhem I (2002) On the rate of translocation in vitro and kinetics in vivo of the major oxysterols in human circulation: critical importance of the position of the oxygen function. J Lipid Res 43:2130-2135.

72. Hughes TM, Rosano C, Evans RW, Kuller LH (2013) Brain cholesterol metabolism, oxysterols, and dementia. J Alzheimers Dis 33:891-911.

73. Papassotiropoulos A, Lütjohann D, Bagli M, Locatelli S, Jessen F, Buschfort R, Ptok U, Björkhem I, von Bergmann K, Heun R (2002) 24S-hydroxycholesterol in cerebrospinal fluid is elevated in early stages of dementia. J Psychiatr Res 36:27-32.

74. Heverin M, Bogdanovic N, Lütjohann D, Bayer T, Pikuleva I, Bretillon L, Diczfalusy U, Winblad B, Björkhem I (2004) Changes in the levels of cerebral and extracerebral sterols in the brain of patients with Alzheimer's disease. J Lipid Res 45:186-193.

75. Shafaati M, Solomon A, Kivipelto M, Björkhem I, Leoni V (2007) Levels of ApoE in cerebrospinal fluid are correlated with Tau and 24S-hydroxycholesterol in patients with cognitive disorders. Neurosci Lett 425:78-82.

76. Björkhem I (2006) Crossing the barrier: oxysterols as choles- terol transporters and metabolic modulators in the brain. J Intern Med 260:493-508.

77. Kim WS, Weickert CS, Garner B (2008) Role of ATP-binding cassette transporters in brain lipid transport and neurological disease. J Neurochem 104:1145-1166.

78. Kim WS, Guillemin GJ, Glaros EN, Lim CK, Garner B (2006) Quantitation of ATP-binding cassette subfamily-A transporter gene expression in primary human brain cells. Neuroreport 17:891-896.

79. Kim WS, Rahmanto AS, Kamili A, Rye KA, Guillemin GJ, Gelissen IC, Jessup W, Hill AF, Garner B (2007) Role of ABCG1 and $A B C A 1$ in regulation of neuronal cholesterol efflux to apolipoprotein E discs and suppression of amyloid-beta peptide generation. J Biol Chem 282:2851-2861.

80. Gosselet F, Candela P, Sevin E, Berezowski V, Cecchelli R, Fenart L (2009) Transcriptional profiles of receptors and transporters involved in brain cholesterol homeostasis at the blood-brain barrier: use of an in vitro model. Brain Res 1249:34-42.

81. Musanti R, Parati E, Lamperti E, Ghiselli G (1993) Decreased cholesterol biosynthesis in fibroblasts from patients with Parkinson disease. Biochem Med Metab Biol 49:133-142.

82. Nakamura K, Mori F, Tanji K, Miki Y, Yamada M, Kakita A, Takahashi H, Utsumi J, Sasaki H, Wakabayashi K (2015) Isopentenyl diphosphate isomerase, a cholesterol synthesizing enzyme, is localized in Lewy bodies. Neuropathology 35:432440.

83. Ikeda K, Nakamura Y, Kiyozuka T, Aoyagi J, Hirayama T, Nagata R, Ito H, Iwamoto K, Murata K, Yoshii Y, Kawabe K, Iwasaki Y (2011) Serological profiles of urate, paraoxonase-1, ferritin and lipid in Parkinson's disease: changes linked to disease progression. Neurodegener Dis 8:252-258.

84. Wei Q, Wang H, Tian Y, Xu F, Chen X, Wang K (2013) Reduced serum levels of triglyceride, very low density lipoprotein cholesterol and apolipoprotein B in Parkinson's disease patients. PLoS One 8:e75743.

85. Guo X, Song W, Chen K, Chen X, Zheng Z, Cao B, Huang R, Zhao B, Wu Y, Shang HF (2015) The serum lipid profile of Parkinson's disease patients: a study from China. Int J Neurosci 125:838-844.

86. Huang X, Chen H, Miller WC, Mailman RB, Woodard JL, Chen PC, Xiang D, Murrow RW, Wang YZ, Poole C (2007) Lower low-density lipoprotein cholesterol levels are associated with Parkinson's disease. Mov Disord 22:377-381.

87. Rozani V, Gurevich T, Giladi N, El-Ad B, Tsamir J, Hemo B, Peretz C (2018) Higher serum cholesterol and decreased Parkinson's disease risk: a statin-free cohort study. Mov Disord 


\section{3:1298-1305.}

88. Huang X, Auinger P, Eberly S, Oakes D, Schwarzschild M, Ascherio A, Mailman R, Chen H (2011) Serum cholesterol and the progression of Parkinson's disease: results from DATATOP. PLoS One 6:e22854.

89. Sterling NW, Lichtenstein M, Lee EY, Lewis MM, Evans A, Eslinger PJ, Du G, Gao X, Chen H, Kong L, Huang X (2016) Higher plasma LDL-cholesterol is associated with preserved executive and fine motor functions in Parkinson's disease. Aging Dis 7:237-245.

90. Tan LC, Methawasin K, Tan EK, Tan JH, Au WL, Yuan JM, Koh WP (2016) Dietary cholesterol, fats and risk of Parkinson's disease in the Singapore Chinese Health Study. J Neurol Neurosurg Psychiatry 87:86-92.

91. Hu G, Antikainen R, Jousilahti P, Kivipelto M, Tuomilehto J (2008) Total cholesterol and the risk of Parkinson disease. Neurology 70:1972-1979.

92. Miyake Y, Sasaki S, Tanaka K, Fukushima W, Kiyohara C, Tsuboi Y, Yamada T, Oeda T, Miki T, Kawamura N, Sakae N, Fukuyama H, Hirota Y, Nagai M (2010) Dietary fat intake and risk of Parkinson's disease: a case-control study in Japan. J Neurol Sci 288:117-122.

93. Cassani E, Cereda E, Barichella M, Madio C, Cancello R, Caccialanza R, Zini M, Cilia R, Pezzoli G (2013) Cardiometabolic factors and disease duration in patients with Parkinson's disease. Nutrition 29:1331-1335.

94. Gudala K, Bansal D, Muthyala H (2013) Role of serum cholesterol in Parkinson's disease: a meta-analysis of evidence. J Parkinsons Dis 3:363-370.

95. Swanson CR, Berlyand Y, Xie SX, Alcalay RN, Chahine LM, Chen-Plotkin AS (2015) Plasma apolipoprotein Al associates with age at onset and motor severity in early Parkinson's disease patients. Mov Disord 30:1648-1656.

96. Qiang JK, Wong YC, Siderowf A, Hurtig HI, Xie SX, Lee VM, Trojanowski JQ, Yearout D, B Leverenz J, Montine TJ, Stern M, Mendick S, Jennings D, Zabetian C, Marek K, Chen-Plotkin AS (2013) Plasma apolipoprotein A1 as a biomarker for Parkinson disease. Ann Neurol 74:119-127.

97. Wilhelmus MM, Bol JG, Van Haastert ES, Rozemuller AJ, Bu G, Drukarch B, Hoozemans JJ (2011) Apolipoprotein E and LRP1 increase early in Parkinson's disease pathogenesis. Am J Pathol 179:2152-2156.

98. Zhao N, Liu CC, Qiao W, Bu G (2018) Apolipoprotein E, receptors, and modulation of Alzheimer's disease. Biol Psychiatry 83:347-357.

99. Zareparsi S, Kaye J, Camicioli R, Grimslid H, Oken B, Litt M, Nutt J, Bird T, Schellenberg G, Payami H (1997) Modulation of the age at onset of Parkinson's disease by apolipoprotein E genotypes. Ann Neurol 42:655-658.

100. Ghebremedhin E, Del Tredici K, Vuksic M, Rüb U, Thal DR, Burbach GJ, Rosenberger A, Bickeböller H, Deller T, de Vos RA, Jansen Steur EN, Braak H (2006) Relationship of apolipoprotein $\mathrm{E}$ and age at onset to Parkinson disease neuropathology. J Neuropathol Exp Neurol 65:116-123.

101. Wakabayashi K, Kakita A, Hayashi S, Okuizumi K, Onodera O, Tanaka H, Ishikawa A, Tsuji S, Takahashi H (1998) Apolipoprotein E epsilon4 allele and progression of cortical Lewy body pathology in Parkinson's disease. Acta Neuropathol 95:450-454.

102. Huang X, Chen PC, Poole C (2004) APOE-[epsilon]2 allele associated with higher prevalence of sporadic Parkinson disease. Neurology 62:2198-2202.

103. Federoff M, Jimenez-Rolando B, Nalls MA, Singleton AB (2012) A large study reveals no association between APOE and Parkinson's disease. Neurobiol Dis 46:389-392.

104. Pierzchlińska A, Białecka M, Kurzawski M, Sławek J (2018) The impact of Apolipoprotein E alleles on cognitive performance in patients with Parkinson's disease. Neurol Neurochir Pol 52:477-482.

105. Lee CY, Seet RC, Huang SH, Long LH, Halliwell B (2009) Different patterns of oxidized lipid products in plasma and urine of dengue fever, stroke, and Parkinson's disease patients: cautions in the use of biomarkers of oxidative stress. Antioxid Redox Signal 11:407-420.

106. Huang X, Sterling NW, Du G, Sun D, Stetter C, Kong L, Zhu Y, Neighbors J, Lewis MM, Chen H, Hohl RJ, Mailman RB (2019) Brain cholesterol metabolism and Parkinson's disease. Mov Disord 34:386-395.

107. Schönknecht P, Lütjohann D, Pantel J, Bardenheuer H, Hartmann T, von Bergmann K, Beyreuther K, Schröder J (2002) Cerebrospinal fluid 24S-hydroxycholesterol is increased in patients with Alzheimer's disease compared to healthy controls. Neurosci Lett 324:83-85.

108. Björkhem I, Lövgren-Sandblom A, Leoni V, Meaney S, Brodin L, Salveson L, Winge K, Pålhagen S, Svenningsson P (2013) Oxysterols and Parkinson's disease: evidence that levels of 24S-hydroxycholesterol in cerebrospinal fluid correlates with the duration of the disease. Neurosci Lett 555:102-105.

109. Fabelo N, Martín V, Santpere G, Marín R, Torrent L, Ferrer I, Díaz M (2011) Severe alterations in lipid composition of frontal cortex lipid rafts from Parkinson's disease and incidental Parkinson's disease. Mol Med 17:1107-1118.

110. Attems J, Jellinger K (2013) Neuropathological correlates of cerebral multimorbidity. Curr Alzheimer Res 10:569-577. 
111. Paul R, Choudhury A, Kumar S, Giri A, Sandhir R, Borah A (2017) Cholesterol contributes to dopamine-neuronal loss in MPTP mouse model of Parkinson's disease: involvement of mitochondrial dysfunctions and oxidative stress. PLoS One 12:e0171285.

112. Raju A, Jaisankar P, Borah A, Mohanakumar KP (2018) 1-methyl-4-phenylpyridinium-induced death of differentiated SH-SY5Y neurons is potentiated by cholesterol. Ann Neurosci 24:243-251.

113. Krüger R, Vieira-Saecker AM, Kuhn W, Berg D, Müller T, Kühnl N, Fuchs GA, Storch A, Hungs M, Woitalla D, Przuntek H, Epplen JT, Schöls L, Riess O (1999) Increased susceptibility to sporadic Parkinson's disease by a certain combined alphasynuclein/apolipoprotein E genotype. Ann Neurol 45:611617.

114. Fantini J, Carlus D, Yahi N (2011) The fusogenic tilted peptide (67-78) of a-synuclein is a cholesterol binding domain. Biochim Biophys Acta 1808:2343-2351.

115. Fortin DL, Troyer MD, Nakamura K, Kubo S, Anthony MD, Edwards RH (2004) Lipid rafts mediate the synaptic localization of alpha-synuclein. J Neurosci 24:6715-6723.

116. Varkey J, Mizuno N, Hegde BG, Cheng N, Steven AC, Langen R (2013) a-Synuclein oligomers with broken helical conformation form lipoprotein nanoparticles. J Biol Chem 288:17620-17630.

117. Emamzadeh FN, Allsop D (2017) a-synuclein interacts with lipoproteins in plasma. J Mol Neurosci 63:165-172.

118. Hsiao JT, Halliday GM, Kim WS (2017) a-synuclein regulates neuronal cholesterol efflux. Molecules 22:E1769.

119. Sui YT, Bullock KM, Erickson MA, Zhang J, Banks WA (2014) Alpha synuclein is transported into and out of the brain by the blood-brain barrier. Peptides 62:197-202.

120. El-Agnaf OM, Salem SA, Paleologou KE, Cooper LJ, Fullwood NJ, Gibson MJ, Curran MD, Court JA, Mann DM, Ikeda S, Cookson MR, Hardy J, Allsop D (2003) Alpha-synuclein implicated in Parkinson's disease is present in extracellular biological fluids, including human plasma. FASEB J 17:19451947.

121. Koob AO, Ubhi K, Paulsson JF, Kelly J, Rockenstein E, Mante M, Adame A, Masliah E (2010) Lovastatin ameliorates alphasynuclein accumulation and oxidation in transgenic mouse models of alpha-synucleinopathies. Exp Neurol 221:267-274.

122. Barceló-Coblijn G, Golovko MY, Weinhofer I, Berger J, Murphy EJ (2007) Brain neutral lipids mass is increased in alphasynuclein gene-ablated mice. J Neurochem 101:132-141.

123. van Maarschalkerweerd A, Vetri V, Vestergaard B (2015) Cholesterol facilitates interactions between $a$-synuclein oligo- mers and charge-neutral membranes. FEBS Lett 589(19 Pt B):2661-2667.

124. Bosco DA, Fowler DM, Zhang Q, Nieva J, Powers ET, Wentworth P Jr, Lerner RA, Kelly JW (2006) Elevated levels of oxidized cholesterol metabolites in Lewy body disease brains accelerate alpha-synuclein fibrilization. Nat Chem Biol 2:249253.

125. Emamzadeh FN, Aojula H, McHugh PC, Allsop D (2016) Effects of different isoforms of apoE on aggregation of the a-synuclein protein implicated in Parkinson's disease. Neurosci Lett 618:146-151.

126. Schommer J, Marwarha G, Schommer T, Flick T, Lund J, Ghribi O (2018) 27-Hydroxycholesterol increases a-synuclein protein levels through proteasomal inhibition in human dopaminergic neurons. BMC Neurosci 19:17.

127. Kitada T, Asakawa S, Hattori N, Matsumine H, Yamamura Y, Minoshima S, Yokochi M, Mizuno Y, Shimizu N (1998) Mutations in the parkin gene cause autosomal recessive juvenile parkinsonism. Nature 392:605-608.

128. Cha SH, Choi YR, Heo CH, Kang SJ, Joe EH, Jou I, Kim HM, Park SM (2015) Loss of parkin promotes lipid rafts-dependent endocytosis through accumulating caveolin-1: implications for Parkinson's disease. Mol Neurodegener 10:63.

129. Kim KY, Stevens MV, Akter MH, Rusk SE, Huang RJ, Cohen A, Noguchi A, Springer D, Bocharov AV, Eggerman TL, Suen DF, Youle RJ, Amar M, Remaley AT, Sack MN (2011) Parkin is a lipid-responsive regulator of fat uptake in mice and mutant human cells. J Clin Invest 121:3701-3712.

130. Oh SE, Mouradian MM (2017) Regulation of signal transduction by DJ-1. Adv Exp Med Biol 1037:97-131.

131. Kim KS, Kim JS, Park JY, Suh YH, Jou I, Joe EH, Park SM (2013) DJ-1 associates with lipid rafts by palmitoylation and regulates lipid rafts-dependent endocytosis in astrocytes. Hum Mol Genet 22:4805-4817.

132. Kim JM, Cha SH, Choi YR, Jou I, Joe EH, Park SM (2016) DJ-1 deficiency impairs glutamate uptake into astrocytes via the regulation of flotillin-1 and caveolin-1 expression. Sci Rep 6:28823.

133. Bae EJ, Kim DK, Kim C, Mante M, Adame A, Rockenstein E, Ulusoy A, Klinkenberg M, Jeong GR, Bae JR, Lee C, Lee HJ, Lee BD, Di Monte DA, Masliah E, Lee SJ (2018) LRRK2 kinase regulates $\alpha$-synuclein propagation via RAB35 phosphorylation. Nat Commun 9:3465.

134. Yamaguchi S, Yamane T, Takahashi-Niki K, Kato I, Niki T, Goldberg MS, Shen J, Ishimoto K, Doi T, Iguchi-Ariga SM, Ariga H (2012) Transcriptional activation of low-density lipoprotein receptor gene by DJ-1 and effect of DJ-1 on cho- 
lesterol homeostasis. PLoS One 7:e38144.

135. Baptista MA, Dave KD, Frasier MA, Sherer TB, Greeley M, Beck MJ, Varsho JS, Parker GA, Moore C, Churchill MJ, Meshul CK, Fiske BK (2013) Loss of leucine-rich repeat kinase 2 (LRRK2) in rats leads to progressive abnormal phenotypes in peripheral organs. PLoS One 8:e80705.

136. Fallon L, Moreau F, Croft BG, Labib N, Gu WJ, Fon EA (2002) Parkin and CASK/LIN-2 associate via a PDZ-mediated interaction and are co-localized in lipid rafts and postsynaptic densities in brain. J Biol Chem 277:486-491.
137. Silvestri L, Caputo V, Bellacchio E, Atorino L, Dallapiccola B, Valente EM, Casari G (2005) Mitochondrial import and enzymatic activity of PINK1 mutants associated to recessive parkinsonism. Hum Mol Genet 14:3477-3492.

138. Hatano T, Kubo S, Imai S, Maeda M, Ishikawa K, Mizuno Y, Hattori N (2007) Leucine-rich repeat kinase 2 associates with lipid rafts. Hum Mol Genet 16:678-690.

139. Kang SJ, Kim JS, Park SM (2018) Ubiquitin C-terminal hydrolase $\mathrm{L} 1$ regulates lipid raft-dependent endocytosis. Exp Neurobiol 27:377-386. 